\title{
TRANSICIONES CURRICULARES EN EDUCACIÓN INTERCULTURAL: DESDE EL ROCK Y EL HIP-HOP, AL CANTO TRADICIONAL MAPUCHE $(\ddot{U} L)^{1}$ \\ Curricular Transitions in Intercultural Education: From \\ Rock and Hip-Hop, to Traditional Mapuche Song (ül)
}

\author{
Amilcar Forno Sparosvich* \\ Ignacio Soto Silva**
}

Resumen

En una aproximación cualitativa y una perspectiva analítica performativa relevamos la presencia de lenguajes musicales diversos en la educación intercultural, teniendo como caso de estudio a educadores tradicionales mapuches que incorporan dispositivos curriculares en escuelas con programas de educación intercultural bilingüe (EIB), localizadas en la ciudad de Puerto Montt (Chile). Nuestras reflexiones principales apuntan al relevamiento de estrategias etnomusicales descolonizadoras puestas en juego en el aula, en las que se evidencia la ampliación de repertorio musical en la noción tradicional del canto mapuche (ül) que manifiestan los docentes. Para los y las docentes entrevistados, esta noción se abre para incluir, entre otros, algunos epewkantun, además de canciones con funciones didácticas (empleadas como recursos mnemotécnicos) y canciones winka, estas últimas en la forma de re-mixtura de expresiones musicales urbanas. Estas nuevas prácticas musicales apuntan a favorecer la reafirmación étnica de sus estudiantes, desde un posicionamiento de identidad mapuche urbana, en ruptura con la noción esencialista de cultura. Estas transiciones curriculares estarían constituyendo un nuevo escenario en las prácticas musicales dentro del aula intercultural, caracterizadas de manera tradicional por la incorporación de canciones políticamente ingenuas.

Palabras clave: Educación Intercultural, Transiciones curriculares, Reafirmación étnica, Descolonización, Performatividad.

\section{Abstract}

From a qualitative approach and a performative analytical perspective, we surveyed the presence of various musical languages, taking as case of study the traditional Mapuche educators who incorporate curricular devices in schools with bilingual education programs (EIB), in Puerto Montt, Chile. Our main reflections point to survey decolonization strategies applied in the classroom, which appeal to the growth of musical repertoire extending the traditional notion of the Mapuche song (ül). For traditional teachers, this new notion includes some epewkantun,

\footnotetext{
${ }^{1}$ Constituye parte de la Tesis de posgrado del coautor del artículo, patrocinada por el autor principal del mismo: "Dispositivos curriculares etnomusicales: el canto y la música como formas de apropiación y descolonización performativa, en escuelas con educación intercultural bilingüe (EIB) de la Región de Los Lagos", Programa de Magíster en Ciencias de la Educación, Universidad de Los Lagos, Osorno. Trabajo realizado en el marco del proyecto FONDECYT 1121024 "Dispositivos curriculares: apropiación y descolonización performativa de la educación intercultural en áreas mapuches".
} 
besides songs with didactic functions (employed as mnemonic resources), and winka (non Mapuche) songs (remix of urban musical expressions). These new musical practices aim at favoring the ethnic reaffirmation of students from a disruptive paradigm with the essentialist notion of culture. These curricular transitions create a new framework in the musical practices in the intercultural education, characterized by the incorporation of "politically naive" songs.

Key words: Intercultural education, Curricular transitions, Ethnic reaffirmation, Decolonization, Performance.

\section{INTRODUCCIÓN}

Este artículo analiza los lenguajes o estilos musicales incorporados en el aula por educadores tradicionales mapuches williches ${ }^{2}$, en escuelas con programas de educación intercultural bilingüe (EIB), ubicadas en Puerto Montt (Chile) y alrededores. El relevamiento de estos lenguajes musicales, utilizados como recursos pedagógicos, $\mathrm{y}$ entendidos como dispositivos curriculares, se sustentó en entrevistas abiertas, con recolección de narrativas espontáneas. En una fase avanzada del terreno se procedió a la reflexión conjunta con los docentes, para la coconstrucción de sentidos respecto de sus prácticas musicales en educación intercultural.

Usamos la noción foucaultiana de dispositivo, como "red de relaciones que se pueden establecer entre elementos heterogéneos" (Castro, 98-99), que exceden el campo discursivo, generando un efecto y cumpliendo una función estratégica (Foucault, 2004). De esta noción desprendimos la de dispositivos curriculares etno-musicales, entendidos como recursos didáctico-pedagógicos desarrollados por los docentes interculturales, que incorporan elementos musicales de origen tradicional mapuche y/o de apropiación cultural mapuche, con el objetivo de fortalecer la identidad de los estudiantes, sentido de pertenencia y reafirmación étnica. Estos dispositivos se caracterizan por vehiculizar discursos y temáticas particulares, las que le otorgan un grado de performatividad, esto es, la capacidad de producir efectos, transmitir un sentido, y un modo propio de ver la realidad, y propiciar, en definitiva, formas de descolonización del quehacer pedagógico.

En anteriores estudios (Forno et. al., 2009; Álvarez-Santullano et. al., 2011) hemos reportado algunas características del contexto laboral del educador tradicional, en un espacio institucional tensionado por relaciones asimétricas de poder. En este contexto, relevamos recursos didáctico-pedagógicos referidos a actividades curriculares y extracurriculares, y otras expresiones lectivas y artísticas no musicales, caracterizadas por la función de "actuar (...), como elementos estratégicos destinados a permitir que los docentes explicit[en] los discursos con que sustentan la educación intercultural" (132), abordando problemáticas no contempladas de manera normal por el currículum intercultural ministerial.

\footnotetext{
${ }^{2}$ El grupo williche corresponde a la facción sureña del pueblo mapuche en Chile, caracterizado por el uso de la variedad dialectal de la lengua mapuche denominada chezugun.
} 
En lo metodológico, esta experiencia se sustentó en un paradigma cualitativo, favoreciendo los procesos dialógicos en la recolección de la información, bajo la forma de un diseño que se reconstruye durante el proceso de investigación y se estructura en tres modalidades: una de naturaleza exploratoria no directiva, que se alterna con una dialógica no estructurada y una fase posterior, más reflexiva y coconstructiva. El muestreo de los educadores tradicionales mapuches, participantes del estudio, se realizó mediante la técnica de "Selección por redes" (Goetz y Le Compte, 99), considerando los siguientes criterios: (1) ser educador tradicional, es decir, estar contratado como docente de lengua y cultura mapuche, en el marco del programa de Educación Intercultural Bilingüe (EIB) de la SECREDUC, Región de Los Lagos; (2) incluir, dentro de su praxis pedagógica intercultural, actividades curriculares vinculadas con la música.

Llevamos a cabo entrevistas abiertas, no dirigidas, de 60 a 80 minutos de duración cada una (Guber, 2001), a un total de cinco educadores tradicionales, en ambientes conversacionales no jerarquizados. Esta fase previa permitió relevar tópicos y categorías emergentes, sobre la base del registro de Memos de Terreno, los que dieron lugar a un listado de temas para abordar en el grupo de entrevistas complementarias, para las que fueron seleccionados tres de los cinco educadores. El tratamiento de tópicos y categorías relevantes del estudio, realizado mediante estas entrevistas, aseguró el abordaje dialógico de las temáticas emergentes señaladas como significativas por los educadores. La posterior sistematización de la información se tradujo en una ponencia presentada en congreso ${ }^{3}$ y fue usada luego como insumo metodológico para la fase final reflexiva y coconstructiva con los dos educadores que mostraron mayor interés respecto del estudio, disponibilidad de acceso, y predisposición a la reflexión crítica. En esta fase se efectuó la devolución y contrastación de información, mediante procesos de reflexión conjunta con los educadores, buscando propiciar la coinvestigación y co-construcción de saberes (Denzin, 2001) en espacios de conversación de tipo dialógico-reflexivos. Estas conversaciones, en torno a los resultados parciales del estudio, permitieron a los docentes manifestar sus posturas, y conceptualizar su realidad, mediante nociones propias y usando conceptos que les fueron significativos, en especial los de "reafirmación cultural", "sincretismo" y "dispositivo curricular".

Esta coconstrucción de conocimientos, llevada a cabo mediante la técnica de retroalimentación de saberes (Miles y Huberman, 1994), permitió constatar la "realidad sociocultural desde la perspectiva de los actores sociales que la construyen" (Quintana y Montgomery, 2006). Esto proporcionó mayor densidad y reflexividad a la investigación.

\footnotetext{
${ }^{3}$ Primer Congreso internacional de educación e interculturalidad RIEDI-2013, Universidad del Bío Bío, Chillán.
} 


\section{TRANSICIONES CURRICULARES}

La apropiación y remixtura de expresiones musicales urbanas se sustenta sobre la base de la ampliación del repertorio musical entendido como $\ddot{u}$, por ello se requiere conocer y comprender, en primera instancia, algunas de sus significaciones y tipologías.

Se denomina $\ddot{u l}$ a un discurso poético mapuche expresado mediante el canto. Para el pueblo mapuche el ül representa la manifestación de la emotividad por parte de quien canta, hacia quienes lo escuchan (Caniguan y Villarroel, 36). Bajo esta premisa, se constituye el ülkantun, que representa la conceptualización del acto de cantar, acto que es llevado a cabo por el ülkantufe (cantor) o la ülkantufe zomo (cantora), quienes, en su contexto cotidiano, establecen mediante un nivel de confianza y cercanía el momento oportuno para la ejecución del canto. El ül tradicional posee variantes en relación con el contexto donde se ejecuta, emergiendo de esa forma diferentes tipos de ül. Carrasco (2000) hace alusión a la diversidad de ül, los que son definidos según criterios pragmáticos. Así se hace posible identificar el machi ül, que hace referencia al canto de las machis; el ngawiwe ül, también llamado cantos de pájaros o pajareros; el kawiñ ül, cantos de fiesta; el kollon ül, que hace alusión al canto de hombres disfrazados; los cantos de trilla o ñuiñn; el paliwe ül, canto de la chueca, y el awarkudewe o cantos de juego de habas (196). Algunas de estas variantes están incorporadas en el currículum oficial del Sector de Lengua Indígena. Además, los educadores tradicionales demostraron conocer gran parte de la variada tipología del canto mapuche:

Los tipos de ül, (...) como el tayül, el epewkantun, el llamekán, entonces, hay mucho, porque la machi también tiene un machi ül que ella solamente utiliza para los ceremoniales. Pichiche ül, que son las canciones solamente de cuna, para hacer dormir a los niños, historias, epewkantun, que es contar los cuentos en forma cantada (E1-1405) .

Para la docente tradicional una forma de $\ddot{u}$ es la del epewkantun, que puede ser considerado como un dispositivo curricular, y que involucra artes escénicas y canto en su constitución.

Yo tenía una súper clase preparada, que era la historia de Kai-kai y Txen-txen vilu, entonces a través del epewkantun, porque ese es un cuento [cantado], hice hasta los títeres, todo (...) llevé hasta el kultxun (E1-1405).

La "historia de Txen-txen y Kai-kai vilu" se sustenta en la utilización del epew tradicional, abordado desde una óptica situada. En este caso la inclusión de elementos musicales derivados del $\ddot{u} l$ permitió la generación de una actividad, que se instaura como un dispositivo curricular etnomusical, que excede lo discursivo, genera un efecto y cumple una función estratégica (Castro, 98-99). En la "historia de Txen-txen

\footnotetext{
${ }^{4}$ En la codificación de las entrevistas se utilizaron los siguientes códigos: E1: № de entrevista / 1405: Fecha de entrevista (día/mes).
} 
y Kai-kai vilu" se advirtió como función estratégica la emergencia de un discurso ligado al cuidado de la biodiversidad marina.

Entonces también les conté que ahora la Kai-kai igual estaba enojada, con el asunto este de la pesca indiscriminada, no cierto, de los productos que sacan estos grandes barcos, y todo eso va ahí, todo eso les va activando a ellos su kimün, entonces yo le dije que antes el mapuche solo recolectaba lo que iba a consumir, y si hacía algún trueque sacaba un poquito más, pero siempre pedía permiso y así se generaba, no cierto el equilibrio, que siempre teníamos que comer, pero estos barcos que arrasan con todo, echan a perder nuestro fondo marino también, toda esa gran biodiversidad que tiene el fondo marino, se muere, y cuesta mucho que se vuelva a recuperar. Entonces todo eso va llevando una enseñanza, para el niño que está ahí pendiente, y que mejor que írselo cantando (E1-1405).

El docente expresa aquí su postura frente a una situación problemática, utilizando el epewkantun como vehículo de un discurso contrario a la pesca industrial indiscriminada, y como elemento facilitador del aprendizaje. El ülkantun se configura de esta manera como un factor fundamental, el cual, mediante la ampliación del repertorio tradicional de $\ddot{u} l$, permite la emergencia de estrategias metodológicas que buscan propiciar espacios de reafirmación étnica, así como también la elaboración de dispositivos curriculares que abordan, desde una óptica tradicional, problemáticas propias del pueblo mapuche.

Otra dimensión emergente en el estudio remite a la utilización de la música popular urbana como un medio de descolonización de los procesos educativos, en una estrategia pedagógica que supera la visión esencialista de la cultura mapuche, haciéndola parte interactuante con el mundo contemporáneo.

El [mapuche] interactúa con los elementos de la ciudad, forma parte de la urbe y es un actor importante en la urbe, es alguien que tiene voz y que se manifiesta por medio de las expresiones culturales o artísticas de la urbe, (...) es el caso del rock o el hip-hop, por ejemplo, que son propiamente urbanos u occidentales, pero que el mapuche se los ha apropiado (E7-2609).

Esta vinculación se establece en cuanto se comprende que el mapuche interactúa con la urbe adoptando los códigos del mundo occidental, en este caso, sus lenguajes musicales. En paralelo a nuestro estudio, podemos constatar estrategias similares a la mapuche por parte de otros pueblos originarios, como reporta Hollands (2004), los jóvenes mohawks canadienses, mediante la adopción del hip-hop, construyen puentes entre sus tradiciones culturales y la modernidad.

Cuestiones de poder se reflejan a través de las relaciones de género, inequidad y racismo, y la dominación de la cultura Americana por sobre la Canadiense, también impacta en la formación de la identidad juvenil Mohawk y plantea desafíos para construir puentes entre las costumbres tradicionales y el mundo moderno (Hollands, 2004, Mi traducción). 
Esto se fundamenta, desde la visión del docente tradicional, como una práctica recurrente dentro del pueblo mapuche, en tanto se relaciona la adopción de recursos tecnológicos y culturales occidentales con acontecimientos paradigmáticos de la historia mapuche.

(...) como lo que pasó con Lautaro, que se apropió del caballo, que aprendió y le enseñó a su pueblo a usar el caballo, cosa que venía de afuera, y así ocurre con un montón de elementos, como el internet por ejemplo, que igual sirve, existen las redes sociales, convocatorias para marchas, para concientizar, protestar, o de última, como una plataforma de opinión, con una dinámica y con un trasfondo mapuche, pero dentro de un contexto winka (E7-2609).

La visión propuesta por el educador tradicional remite a una pertenencia urbana en la que resulta legítimo el uso de los recursos tecnológicos y lenguajes actuales para manifestarse desde el mundo mapuche, sustentando una identidad que se construye como distinta a lo winka. Los procesos de remixtura ${ }^{5}$ o hibridación permiten, entonces, reconocer en el uso de la música y las tecnologías un medio válido para abordar la problemática mapuche en un mundo globalizado, y generar nuevos modelos de comunidad mapuche, en una estrategia sincrética glocalizada y dinámica, que mezcla lo global y lo local, lo contemporáneo y lo tradicional.

De acuerdo con lo anterior, comprender el concepto de $\ddot{u l}$ desde una realidad urbana y contemporánea, implica ampliar la visión del mismo, sin perder el sentido del ser mapuche. Los educadores tradicionales williche tienen una clara conciencia de esta situación:

En el fondo aquí se produce un proceso de sincretismo, porque nosotros no somos islas, ni podemos apartarnos, estamos insertos en una sociedad que tiene sus normas y tiene sus códigos, sin embargo uno puede reinventarlas, reencauzarlas, alterarlas y darles otra significación. Esa es la posibilidad, la virtud que nos da en definitiva la modernidad (E7-2609).

Como hemos podido observar, la apertura conceptual del $\ddot{u} l$ permite la adopción de música popular urbana, y su aplicación en el aula intercultural como elementos válidos para la enseñanza de la cultura mapuche, pero también admite la incorporación curricular de expresiones musicales mapuches de corte moderno o posmoderno, de música y canciones mapuches que pasan a constituir una versión estilizada u occidental del $\ddot{u} l$, como podemos ver en la siguiente cita:

He recurrido a una banda de Chiloé que se llama Armazón, es un proyecto que sacaron un disco que se llama el Ülkantun, es un disco de un canto ceremonial mapuche de Chiloé, una fusión muy buena, así música posmoderna, con sintetizadores y todo, con Kultxunes y Txutxukas. Elementos como esos, de ahí

\footnotetext{
${ }^{5}$ Según Lashua (2006) "El remix comparte algunas afinidades con los conceptos de hibridación y bricolage" (6, mi traducción).
} 
está minuto soler o minuto solar, es una cosa de hip-hop, hay otro los Wechekeche Ni Trawün también, que son más por el lado del reguetón y cosas así, pero en lengua, Sofía Painequeo, que es como una cantora mapuche tradicional, Armando Nahuelpan, esos son como nombres que aparecen. Bueno y de afuera he usado también, de la argentina Beatriz Pichi Malen (E7-2609).

En definitiva, esta ampliación del repertorio que el docente considera $\ddot{u} l$ resulta vital para la elaboración de las estrategias descolonizadoras puestas en juego en el aula, ya que posibilita mixturas con incorporación de códigos urbanos conocidos y valorados por los estudiantes.

Dentro del trabajo de interculturalidad, se ha ido resignificando el $u ̈ l$, adaptándolo a las nuevas generaciones, que son los niños que quieren conocer, pero que no tienen los códigos antiguos, entonces tú utilizas los códigos propios para encauzar la temática hacia el rescate de lo ancestral, del concepto ancestral y eso se logra muy bien, como te digo en el caso de trabajar y traducir una canción de cuna, con las partes del cuerpo donde los niños realmente jugando aprenden como son sus partes, en el fondo tú de ahí innegablemente en ese proceso involucras, o inculcas, un respeto, un proceso de interculturalidad que tiene que ver con una convivencia armónica entre dos culturas (E7-2609).

Para ejemplificar lo anterior, un dispositivo curricular que podemos denominar "hip-hop de los huesos", nos muestra una estrategia sincrética, en la que se usa la música popular urbana occidental para enseñar vocabulario mapuche.

Últimamente hicimos un hip-hop con los niños, les enseñé las partes de los huesos, y como son medios cuáticos, leg-leg, kira-kira, por ejemplo el cráneo, kira-kira, kusiforo, la columna; kasiforo, las costillas. Entonces con un ritmo de tambor, ya miren cabros aprendamos un hip-hop [Cantando] leg-leg, kira-kira, $\mathrm{y}$ todos bailando, ensayando cosas y aprendiendo los huesos (E7-2609).

También pudimos relevar el uso de una canción folclórica para facilitar el aprendizaje de contenidos propios del currículum intercultural, recurso que denominamos "actividad del lawen", el que, a su vez, actúa como una herramienta pedagógica integradora y activadora de conocimientos previos. El mensaje implícito de la actividad hace alusión a los procesos de integración cultural, ya que se apela a los conocimientos del niño en cuanto a su contexto urbano, para la inclusión de temáticas pertenecientes a la cultura mapuche.

Ahí utilizo eso que yo te decía de este un ül winka que dice: yo curo todos los males, yo curo todas las penas. Las curo con puras hierbas, las curo con hierbabuena [cantado] y ahí va repitiendo la cacha del agua, la del platero, romero blanco, la del puchero. Flores de malva, flor de amapola, tilo, borraja, la cochicola [cantado] (E1-1405).

Se puede observar aquí otra forma de ampliación del repertorio musical asociado al $\ddot{u} l$. En esta actividad se adopta una canción occidental y se presenta dentro 
del aula como una herramienta válida para la enseñanza de tópicos propios de la cultura mapuche. En la visión de esta docente tradicional, la estrategia reseñada le permite trabajar con lenguajes y códigos más cercanos a los alumnos, propiciando así una enseñanza sentida como propia.

Y ahí se genera todo eso, entonces ellos con sus ramitas las olfatean (SIC) ven que hay unas más verdes, otras más pálidas, unas que tienen mal olor, otras que tienen rico olor (...) y yo les voy preguntando también si la mamá, cuando se enferman de la guatita qué les dan, y ahí ya se va generando eso. "No, si a mí me dan poleo o menta" eso lo conocen. Son plantas introducidas pero también se utilizan (E1-1405).

Otra estrategia suele consistir en la inclusión de música folclórica infantil como recurso en la construcción de estrategias metodológicas para abordar temáticas propias del currículum oficial, como el pichiche ül, al que se refiere un educador tradicional:

Por ejemplo una canción de cuna que es de una cantante muy famosa que es la Beatriz Pichi Malen, esa cantante realizó una canción muy buena para los niños y que uno la escucha y dice, claro, sirve, porque son métodos más fáciles (E32806).

En las entrevistas y espacios de reflexión hemos ido viendo cómo quedaron de manifiesto recursos de reunión sincrética y recreación estética de elementos mapuches y no mapuches para la construcción de recursos didácticos aplicados en el aula intercultural. Una ilustración de este tipo de mixtura, es narrada así por un educador:

Por ejemplo en instancias que he hecho, he mostrado a algunos chicos hip-hop en mapudungun, por ejemplo, o rock también, que son elementos tradicionales presentes en expresiones modernas, o sea con el mismo lenguaje [que] están acostumbrados a ver en estos puertorriqueños, entonces les genera un cambio de generación (...). Ver cómo ese choque los saca, cómo esa música no pertenece solamente a otros, sino que es algo propio (E2-2005).

Las estrategias pedagógicas relevadas en este estudio se caracterizaron por romper las dinámicas tradicionales de la clase, mediante el otorgamiento de mayores espacios de movimiento, el desarrollo de clases más dinámicas, activas, participativas, propiciando instancias lúdicas que vinculan la música y el canto con los aprendizajes. Todo ello permite que los estudiantes se involucren y vivan el proceso de enseñanzaaprendizaje en un ambiente estimulante, que propicia su acercamiento a la cultura mapuche.

(...) cuando llego a la sala todos los niños se ponen a saltar, es una felicidad porque llegó el que quiebra el paradigma, yo creo que pasa por ahí, nosotros si queremos dejar una trascendencia y ser un aporte, hay que quebrar los paradigmas (E2-2005). 
La valoración de estas estrategias, por parte de los estudiantes, resulta un factor clave en el éxito de la aplicación en aula de dispositivos curriculares con inclusión de diversos lenguajes musicales. En este sentido, la incorporación de manifestaciones musicales pertenecientes al mundo urbano, que son significativas para los estudiantes, hace posible la puesta en valor de lo mapuche, como elemento en diálogo igualitario con el rock y el hip-hop. La capacidad transformadora o función performativa de estos dispositivos didáctico-pedagógicos apunta de manera específica a la reafirmación étnica de los jóvenes. Estudios realizados en las comunidades Mohawks, de Canadá, reportan similares resultados respecto del uso de la música popular urbana como dispositivo de reafirmación identitaria: "Los jóvenes Mohawks son consumidores activos de la cultura de medios, lo que estratégicamente refuerza y extiende su identidad juvenil nativa" (Holland, 2004, mi traducción). Otro investigador plantea que "Para muchos jóvenes aborígenes, la cultura hip-hop articula las problemáticas y las luchas en sus vidas" (Lashua, 2006, mi traducción).

La problemática de los estereotipos, entendidos como un conjunto de creencias que los miembros de un grupo comparten en torno a los atributos que caracterizan a los miembros de otro grupo (Fiske, 1998 citado en: Saiz; Merino y Quilaqueo, 2009), se acentúa en el aula, ya que los alumnos reciben percepciones estereotipadas del ser mapuche, ya sea en sus hogares o por parte de los medios de comunicación masiva. Junto con las visiones estereotipadas de tipo esencialista existen otras que vienen siendo alimentadas por los medios y que se vinculan a las problemáticas del conflicto mapuche-sociedad winka.

A mí me pasó en una escuela con niños chicos, [al] preguntarles (...) qué saben de los mapuches (...) un niñito dijo "son malos porque queman las casas", o sea y eso es lisa y llanamente, por lo que ven en la tele (E2-2005).

Los educadores tradicionales deben lidiar con estereotipos y prejuicios propiciados muchas veces por los medios, que son coherentes con el contexto de desigualdad social prevaleciente y muchas veces resultan armónicos con intereses de importantes grupos económicos. Frente al rol de los medios de comunicación, en tanto generadores de estereotipos del mapuche contemporáneo, Saiz, Rapimán y Mladinic (2008) hacen alusión al rol de la enseñanza oficial de la historia nacional y cómo los medios de comunicación social parecen estimular el aprendizaje y la conservación de estos estereotipos (Pilleux, 2002; Quilaqueo \& Merino, 2003). Por su parte, Bengoa (1986) menciona que estos estereotipos simplifican, de alguna manera la realidad, "generalmente la deforma[n], no explican las causas y [el] contexto de esa característica $\mathrm{y}$, por lo general, obedecen a intereses que no son justamente el conocimiento de ese grupo humano" (122). Barros (2009) menciona al respecto que estas representaciones estereotipadas del pueblo mapuche nos hablan de una compleja situación, la que vacila entre la idealización de una cultura ancestral (esencialismo) y el estigma del terrorismo (conflicto), propiciado a toda costa por los medios de comunicación (30). Este discurso no se condice con el conocimiento en torno al 
devenir histórico del pueblo mapuche. Saiz, Merino y Quilaqueo (2009) señalan que la falta de entendimiento de parte de los no mapuches hacia los mapuches emerge como resultante de los discursos perpetuados por los medios de comunicación, y se enmarca como un elemento relevante en la construcción de un imaginario estereotipado negativo del pueblo mapuche.

Dichas percepciones, presentes también en las mismas comunidades y dirigencia indígena, generan movimientos de oposición o resistencia que se articulan, desde los márgenes del mundo mapuche y no mapuche, y que tienen como finalidad el crear conciencia de la diversidad e instaurar una visión dinámica del pueblo mapuche, inmerso en un mundo global.

Esta caricaturización de la cultura en el fondo nos está generando un ideal, o imagen que no es real, porque se le ve al mapuche precisamente como que todavía vive en las rucas, que todavía anda a pata pelá y que es borracho, o sea (...) (E2-2005).

Como respuesta, desde la micropolítica de la escuela, los educadores tradicionales construyen una nueva mirada del ser mapuche. Junto con reunir de manera sincrética y recrear estéticamente elementos musicales mapuches y no mapuches, generan una ruptura con la visión estereotipada y esencialista de la cultura en general, y de la cultura mapuche en particular, estereotipo habitual en gran parte de la sociedad y del profesorado. Esta visión esencialista, que permea los programas y proyectos de innovación educativa y de desarrollo comunitario, pone el énfasis en "rescatar" lo más autóctono, tradicional y "puro" de la cultura, como única forma de preservar una identidad cultural y una "cultura" más bien museística, estática, que no responde a la realidad cotidiana familiar y comunitaria mapuche actual. En oposición a ello, el recurso sincrético de lenguajes musicales mapuches y urbanos rompe estos estereotipos y esencialismos e incorpora una visión más abierta y actual del ser mapuche. Como señala un entrevistado:

(...) ahora existe el mapuche que es profesional, el mapuche urbano, el mapuche que vive en el campo pero que hace otras cosas, o sea abierto, y en este proceso de interculturalidad, se evidenciaría esto, cuando se dejan esos estereotipos de lado, más o menos ese es el tema (E2-2005).

La reafirmación identitaria propiciada por los educadores, en la medida en que promueve una visión descolonizadora del ser mapuche, rompe entonces con las imágenes estereotipadas impuestas, tanto con la esencialista o museológica, como con la de violencia y conflicto permanente, difundida por los medios de comunicación. Sobre esta base, los educadores tradicionales mapuches williches reconocen e incorporan en el currículum el dinamismo propio de los procesos de interculturalidad, dinamismo que genera la posibilidad de crear una nueva visión del ser mapuche como sujeto moderno y urbano. Todo este esfuerzo decolonizador se ubica en la línea de 
reforzamiento de la identidad cultural y la etnicidad, como ha sido el espíritu de la Ley Indígena. Al respecto Larraín puntualiza:

Aunque el proceso de aculturación esté siempre en marcha, y de hecho sea imparable (como todo proceso aculturativo), el nuevo tipo de educación intercultural que se pretende introducir (en el marco de los artículos 32 y 33 de la Ley Indígena de 1993), fomentado por maestros de marcada vocación indígena, puede y debe incentivar una vuelta a las raíces culturales y un reforzamiento de la identidad cultural propia de la etnia (Larraín, 8).

\section{CONCLUSIONES}

La convivencia entre las concepciones winka y mapuche, que se desprende de la información recogida a lo largo de este estudio, puede ser interpretada como un entramado de relaciones que potencia procesos de reafirmación étnica en jóvenes que se encuentran, ya sea por influencia de los medios de comunicación masiva o por razones de historia familiar o influjo social, alejados de la tradición cultural mapuche.

Las estrategias pedagógicas del educador tradicional, para potenciar la identidad mapuche en sus estudiantes, se caracteriza por incluir, junto con o antes de la música mapuche, elementos musicales característicos de su entorno urbano y del ámbito juvenil, en cuanto a elección de las estéticas a usar. Entre ellos se observó el hip-hop, el rock y la fusión tradicional como elementos incorporados en la elaboración de recursos pedagógicos, lo que expresa autonomía curricular y una estrategia particular en el ejercicio pedagógico del educador tradicional.

Estas expresiones se pudieron observar, en el transcurso de la investigación, en la elaboración de estrategias didácticas, mostrando una forma particular de concebir el proceso de enseñanza aprendizaje por parte del docente tradicional mapuche, cuya cultura musical se ve influenciada por los paradigmas imperantes en la cultura artística urbana.

Es posible inferir que estas prácticas pedagógicas, manifestadas por los educadores tradicionales mapuches, configuran una transición curricular que va desde un acercamiento a estéticas rupturistas (hip-hop y rock), hasta lograr el objetivo de que los estudiantes asuman como propias manifestaciones tradicionales de la música mapuche, pasando por distintas formas de hibridación y remixturas de lenguajes musicales urbanos, como ocurre en los hallazgos de Hollands (2004) y Lashua (2006).

Hemos interpretado estos recursos y estas estrategias curriculares como elementos que apuntan a descolonizar el currículum, generando discursos otros (Mignolo, 1996; Castro-Gómez, 2005), mediante la incorporación de temáticas identitarias y sincretismo de estilos musicales mapuches y urbanos, en un enfoque opuesto a la noción esencialista de cultura y a los estereotipos mediáticos.

La hibridación y remixtura de estos lenguajes en recursos pedagógicos, usados en el aula intercultural, puede ser explicada sobre la base de los aspectos relacionales y comunes que comparten. Relevamos como aspectos más representativos de este vínculo la espontaneidad y la improvisación basándose en lo cotidiano, la imposición 
del ritmo de la percusión sobre lo melódico y el posicionamiento rupturista de los discursos o letras cantadas.

Así, en el caso del ül (canción tradicional mapuche) y el hip-hop (música urbana actual) constituyen manifestaciones espontáneas, que buscan desde la improvisación plasmar un discurso vinculado a la cotidianeidad. En esta línea Tijoux, Facuse y Urrutia (2012), hablando del hip-hop, indican que “(...) la improvisación resulta aquí un elemento fundamental gracias a la instantaneidad del relato que permite a los artistas trabajar una experiencia colectiva". Esta característica del hiphop guarda relación con el trasfondo simbólico del $u ̈ l$, el que también se construye desde la improvisación. Al respecto, Painequeo (2012) describe que el ülkantufe "reflexiona profundamente, se interna en su propio ser como si soñara (...) hasta que va encontrando la forma de lenguaje que empleará para expresar lo que piensa" (205). La improvisación funciona como un nexo entre las características en la construcción del relato sonoro del hip-hop y las formas de componer un ülkantun en un contexto tradicional, expresando esta conexión en la praxis pedagógica del docente tradicional.

Desde otra perspectiva, tanto el hip-hop, como la música tradicional mapuche privilegian lo percusivo y periódico como característica de base. Esta coincidencia es rescatada por los investigadores Ojamaa y Ross (2009) de la Académica de Música y Teatro de Estonia (Eesti Muusika- ja Teatriakadeemia), quienes señalan la vinculación del hip-hop con manifestaciones propias de pueblos originarios de China, India y África. "El nacimiento del beatbox creó un nuevo instrumento, la boca. En realidad, la imitación de las percusiones ha existido en la música tradicional, desde mucho antes que el hip-hop (India, China, África)" (139, mi traducción).

Otra característica de base de las estéticas urbanas como el rock (y el hip-hop) es su posicionamiento rupturista. En este sentido Linconao menciona que "el rock se presenta como un movimiento contracultural de personalidad rebelde, existencialista y reaccionario en cuanto a los procesos ocurridos entre la primera y segunda guerra mundial" (1). Esta visión rupturista, facilita la transmisión de discursos de crítica social, lo que explica el por qué de la presencia de estéticas relacionadas al rock y al hip-hop, y su incorporación en la praxis pedagógica de los docentes tradicionales mapuches. Por su parte, el ül, en sus expresiones concretas o ülkantun incorpora también problemáticas o críticas sociales, como el caso presentado de la educadora transicional que incorpora como recurso pedagógico un epewlkantun con la temática mítica de Txen Txen y Kai Kai Vilu, en la que releva un discurso ligado a la protección de la biodiversidad marina.

Podemos concluir que estas transiciones curriculares abren un nuevo escenario en las prácticas musicales del educador tradicional mapuche y representan un avance frente a la escuela que recién se inicia en EIB y conserva un repertorio musical restringido y políticamente ingenuo. En contraste, la apertura del repertorio musical entendido como $\ddot{u} l$ a los epewkantun, además de canciones con funciones didácticas (empleadas como recursos mnemotécnicos) y canciones winka de diverso estilo, 
favorece estéticas musicales más libres y menos "controladas", que permiten improvisación y expresión de contextualidades locales, lo que propicia una vía inédita de descolonización curricular para la escuela intercultural.

Universidad de Los Lagos*

Departamento de Educación

Programa de Estudios Indígenas e Interculturales Avda. Alcalde Fuchslocher 1305. Osorno (Chile) aforno@ulagos.cl

Universidad de Los Lagos** Escuela de Pedagogía Pedagogía en Educación Media en Artes, mención Música Guillermo Gallardo 269, Puerto Montt (Chile) ignacio.soto@ulagos.cl

\section{OBRAS CITADAS}

Álvarez-Santullano, P; Alves, A; Forno, A; Rivera, R; y Fuenzalida, P. "Saberes y anclajes de la escuela intercultural en contexto mapuche: silencios, intermitencias y estrategias en la transmisión del legado histórico". ALPHA 32 (2011): 127-48.

Barros, J. "La(s) identidad(es) mapuche(s) desde la ciudad global en mapurbe venganza a raíz de David Aniñir". Revista Chilena de Literatura [en línea], 75 (2009): 29-46. Web. Rev. 15 de Nov. 2012. <http://www.scielo.cl/scielo.php?pid=S0718$52009000200002 \&$ script $=$ sci_arttext $>$

Bengoa, J. "Sociedad criolla, sociedad indígena y mestizaje". Proposiciones No 12. (1986): 121-139.

Caniguan, N., y Villarroel, F. Muñkupe ülkantun, que el canto llegue a todas partes: Memoria Chilena. Santiago: LOM, 2011.

Carrasco, I. "Poesía mapuche etnocultural". Anales de literatura chilena I. 1(2000):185-214.

Castro, E. El vocabulario de Michel Foucault. Un recorrido alfabético por sus temas, conceptos y autores. Buenos Aires: Universidad de Quilmes, 2004.

Castro-Gómez, S. La poscolonialidad explicada a los niños. Colombia: Editorial Universidad del Cauca, 2005.

Denzin, N. "The reflexive interview and a performative social science". Qualitative Research, 1(1) (2001): 23-46.

Forno, A; Álvarez-Santullano, P; y Rivera, R. "Entre el edificio y el currículum de la interculturalidad: una mirada antropológica a la educación actual en el territorio mapuche-huilliche". Chungará, 41(2) (2009): 287-298.

Foucault, M. El orden del discurso. Buenos Aires: Fábula Tusquests, 2004.

Goetz, J., and M. Le Compte. Etnografia y diseño cualitativo en investigación educativa. Madrid: Morata, 1988. 
Guber, R. La etnografia. Método, campo y reflexividad. Buenos Aires: Siglo XXI, 2011 Hollands, R. "'Rappin' on the reservation: Canadian mohawk youth's hybrid cultural Identities”. Sociological Research Online, 9(3) (2004). Web. Rev. 5 Nov. 2013. Disponible en: http://www.socresonline.org.uk/9/3/hollands.html

Lashua, B. "The arts of the remix: ethnography and rap". Anthropology Matters 8 (2) (2009). Rev. 15 de sep. 2012. Disponible en:

http:/www.anthropologymatters.com/index.php/anth_matters/article/view/67/129

Larraín, H. "Los por qué de la interculturalidad: argumentos para la adopción de una Educación Intercultural Bilingüe". Revista de Ciencias Sociales Universidad Arturo Prat 7 (1997): 3-15.

Linconao, P. Rock Mapuche. Hibridación cultural-memoria histórica. Centro de Documentación Nuke Mapuförlaget, 2011. Web. Rev.15 sept. 2012. Disponible en: www.mapuche.info/wps pdf/sepulveda20111127.pdf

Mignolo, W. D. "Herencias coloniales y teorías poscoloniales”, en: B. González Stephan (Ed.), Cultura y Tercer Mundo. Cambios en el saber académico, Caracas: Nueva Sociedad, 1996: 99-136.

Miles, M. y Huberman, A. Qualitative data analysis: an expanded sourcebook Thousand, CA: Sage. 1994.

MINEDUC. Marco Curricular Asignatura de Lengua Indígena, 2009.

Ojamaa, R; Ross, J. "Sound and timing must be perfect. Production aspects of the human beatboxing". 5th Conference on Interdisciplinary Musicology. Institut Jean le Rond d'Alembert, París (2009): 134 - 135

Painequeo, H. "Técnicas de composición en el ÜL (canto mapuche)". Literatura y lingüistica, 26 (2012): 205-228. Web. Rev. 10 de Nov. 2012. Disponible en: http://www.scielo.cl/scielo.php?script=sci_arttext\&pid=S071658112012000200013

Pilleux, M. "La educación y el prejuicio étnico". Contexto Educativo 24 (2002). Web. Rev. 2 Oct. 2013. Disponible en: http://contexto-educativo.com.ar/2002/4/nota-07.htm

Quilaqueo, D. y Merino, M. E. "Estereotipos y prejuicio étnico hacia los mapuches en textos complementarios a la asignatura de Historia". Campo Abierto, 23, (2003): 119-135.

Quintana, A. y Montgomery, W. (Eds.) Psicología: Tópicos de actualidad. Lima: UNMSM, 2006

Saiz, J; Merino, M; Quilaqueo, D. "Meta-estereotipos sobre los indígenas mapuches de Chile". Interdisciplinaria $1 \mathrm{~N}^{\mathrm{0}} 26$ (2009): $23-48$.

Saiz, J; Rapimán, M; y Mladinic, A. "Estereotipos sobre los mapuches: su reciente evolución". Psykhe (Santiago), 17(2) (2008): 27-40.

Tijoux, M; Facuse, M; y Urrutia, M. "El hip hop: ¿Arte popular de lo cotidiano o resistencia táctica a la marginación?". Polis 11(33) (2012): 429-450. 